\title{
Comentário a \\ “O externalismo semiótico ativo de C. S. Peirce e a CANTORIA DE VIOLA COMO SIGNO EM AÇÃO”
}

\author{
Max Rogerio Vicentini ${ }^{1}$
}

Referência do artigo comentado: ATÁ, P; QUEIROZ, J. O externalismo semiótico ativo de C. S. Peirce e a cantoria de viola como signo em ação. Trans/Form/Açáo: revista de filosofia da Unesp, v. 44, n. 3, p. 177-204, 2021.

O externalismo cognitivo pode ser entendido como a tese de que as características do ambiente físico, social e cultural de um agente são elementos constitutivos do sistema cognitivo desse agente. Nesse sentido, o conteúdo de estados mentais, por exemplo, crenças e desejos, podem, pelo menos em parte, depender constitutivamente das características do ambiente físico, social e cultural de um agente (PAOLUCCI, 2011). A principal contribuição do artigo de Pedro Atã e João Queiroz é, como indicado pelos próprios autores,

[...] fornecer uma ontologia semiótica para o externalismo cognitivo ativo [ao argumentar em favor da tese de que] a unidade fundamental de explicação para o comportamento de indivíduos e artefatos, em um SCD [Sistema Cognitivo Distribuído], [...], é a semiose, coordenando indivíduos e artefatos em comportamentos regulares. (ATÃ; QUEIROZ, 2021, p. 177-178).

${ }_{1}$ Professor na Universidade Estadual de Maringá (UEM), Maringá, PR - Brasil. (DD https://orcid. org/0000-0001-8257-7273. E-mail: mrvicentini@uem.br.

https://doi.org/10.1590/0101-3173.2021.v44n3.17.p211

\section{(i)}


O objetivo, dessa maneira expresso, mobiliza os conceitos em torno dos quais o texto se constrói. Trata-se, ao mesmo tempo, de fornecer uma abordagem mais completa dos SCDs, a qual supre as carências identificadas nas perspectivas presentes na bibliografia especializada sobre o tema e de, ao caracterizá-lo como um sistema semiótico, explicitar os elementos fundamentais desse tipo de sistema. Busca, portanto, oferecer uma contribuição para a definição dos sistemas cognitivos distribuídos e representa um esforço para tornar claro, por meio de um caso exemplar, o desafio dos repentistas ou cantiga de viola, os elementos envolvidos nos processos adequadamente denominados semióticos.

A síntese da revisão bibliográfica revela os progressos obtidos na tentativa de oferecer uma descrição mais adequada dos SCDs. Os autores apresentam a perspectiva centrada no indivíduo; a perspectiva enculturada, entendida como a cognição que acontece em ecossistemas culturais com a participação de múltiplos indivíduos e artefatos; a perspectiva emergentista, centrada no próprio sistema como principal elemento explanatório e, por fim, a "abordagem baseada em tarefas", a qual, embora desloque o indivíduo do centro da realização dos SCDs, deixa em aberto questóes sobre a natureza cognitiva das tarefas e o processamento de informação nela envolvido. Embora exista o claro reconhecimento da necessidade de "[...] enculturar a abordagem externalista, o paradigma ainda não considerou seriamente que SCDs incorporam significados, e não simplesmente processamento de informaçôes." (ATÃ; QUEIROZ, 2021). Para suprir essa lacuna, os autores sugerem a noção peirciana de semiose ou ação de signos como fundamento para a ontologia de tais sistemas, cujo autor é apresentado como um precursor da perspectiva do externalismo cognitivo ativo, por centrar sua compreensão do processo cognitivo na ação dos signos.

O modo como ocorrem as cantorias ou repentes é exposto com riqueza de detalhes e se torna evidente a sua natureza de $S C D$, a se realizar sua descrição a partir dos elementos constituintes das definiçóes disponíveis sobre tais sistemas; contudo, os autores explicitam que a tarefa permanece incompleta, pois, a partir da perspectiva peirciana, um elemento fundamental não foi tocado: o fato de que, no repente, não há apenas trocas informacionais ou realização de tarefas cognitivas, mas um processo essencialmente significativo. De modo muito claro e convincente, os autores mostram a pertinência de sua descrição semiótica do repente como um caso exemplar de um fenômeno cuja natureza é processual e ocorre por meio da ação de 
signos. Nele, o signo age sobre indivíduos e objetos para a manifestação do repente. Não são os indivíduos e objetos que se organizam para a produçáo da cantoria repentista, todavia, esta se desenvolve semioticamente e se utiliza dos indivíduos e objetos para se manifestar. Investigar e descrever os elementos envolvidos e seus comportamentos equivale a investigar e descrever o próprio processo semiótico; é, em suma, metassemiótica.

Essa é uma contribuição robusta, pois sugere, de modo sintético e compreensivo, os meios para se fornecer uma definição mais abrangente dos SCD, por meio da ontologia processual disponível na semiótica de matriz peirciana. Em síntese, a cantoria é um processo distribuído, porque atua como um processo semiótico, quer dizer, um processo externo e distribuído.

Reconstruindo de modo rápido os momentos do artigo, podemos dizer que os autores partem do problema de se tratar de forma adequada dos SCDs, caracterizando-os a partir de exemplos que sugerem tratar-se de fenômenos com características próprias e especiais. Constatam a insuficiência das abordagens disponíveis na bibliografia especializada e procuram, por meio da teoria semiótica de matriz peirciana, suprir tais lacunas. Os detalhes dessa proposta são apresentados claramente, por meio da análise de um exemplo, o das cantorias ou repentes. Primeiro, mostram que o repente consiste em um SCD e, depois, que é um SCD, porque se trata de um processo de ação de signos, ou semiose. A semiose, contudo, é considerada por Peirce [CP 5.448 n. 1, 1905] como o processo de crescimento do próprio universo. Peirce indica que o universo está repleto de signos, se não for composto unicamente por signos.

Ora, a partir dessa leitura, poderíamos nos perguntar sobre a especificidade dos SCDs, pois, ao indicar que eles são instanciaçôes dos processos de atuação de signos ou semiose, parece-nos que a consequência é a de que o próprio universo seria um SCD e que, portanto, todos os processos de crescimento poderiam adequadamente receber a ontologia semiótica aqui proposta. Se os SCD, como o repente, guardam uma especificidade, caberia apontar qual a sua diferença específica. Uma discussão fascinante, que mobilizaria outros conceitos da teoria peirciana dos signos. 


\section{REFERÊNCIAS}

ATÃ, P.; QUEIROZ, J. O externalismo semiótico ativo de C. S. Peirce e a cantoria de viola como signo em ação. Trans/Form/Açáo: revista de filosofia da Unesp, v. 44, n. 3, p. 177-204, 2021.

PAOLUCCI, C. The "External Mind": Semiotics, Pragmatism, Extended Mind and Distributed Cognition. Versus: quaderni di studi semiotici, n. 112-113, p. 69-96, 2011. PEIRCE, C. S. Collected papers of Charles Sanders Peirce. Ed. by C. Hartshorne e P. Weiss (v. 1-6); A. Burks (v. 7-8). Cambridge, MA: Harvard University Press, 1931-1958. v. 8 . 